\title{
Uji Ketahanan Luntur dan Karakterisasi Serbuk Tinta Cumi-Cumi (Loligo sp.) sebagai Dasar Pewarna Hitam untuk Kain Tenun Ikat Asal Nusa Tenggara Timur
}

Colour Fastness Test and Characterization of Squid Ink Powder (Loligo sp.) as The Base of Black Dyes of Woven Fabric from East Nusa Tenggara

\author{
Merpiseldin Nitsae $^{1 *}$, Egertha Karpada ${ }^{1}$, Arsun Banamtuan ${ }^{1}$, Mellissa E. S. Ledo ${ }^{1}$, Ronny \\ S. Mauboy ${ }^{2}$, Alan Ch. Sabuna ${ }^{*}$ \\ ${ }^{1)}$ Program Studi Pendidikan Biologi, FKIP, Universitas Kristen Artha Wacana Kupang, Kupang-NTT \\ ${ }^{2)}$ Program Studi Biologi, Fakultas Sains dan Teknik, Universitas Nusa Cendana Kupang, Kupang-NTT \\ E-mail:merpinitsae@gmail.com; alan.sabuna@gmail.com *Penulis untuk korespondensi
}

\begin{abstract}
The aims of this research are to examine the nature of the fading and the characteristic of squid ink powder. To examine the colour fastness test, the researchused Gray scale and Staining scale methods while for characterization of squid ink FT-IR and SEM method was used. The result showed that when the cotton cloth was immersed into $250 \mathrm{~mL}$ of squid ink for an hour, it would produce black color but it faded easily. Therefore, it needed to be maintained using a fixator as superficial lime and alum. The variation of fixator concentrations that used was 20,50 , and 100 $\mathrm{g} \mathrm{mL}^{-1}$. The result showed that for each type of fixator superficial lime produced brown color while alum produced dark color. The results test using Gray Scale and Staining Scale methods showed that the best treatment was at $100 \mathrm{~g} \mathrm{~mL}^{-1}$. Besides, the result of squid ink characterization using FT-IR showed that there was an absorption at peak $3236,33 \mathrm{~cm}^{-1}$ is an interaction between -OH cluster and -NH cluster ; 2964, $39 \mathrm{~cm}^{-1}$ and $2927,74 \mathrm{~cm}^{-1}$ are clusters of $\mathrm{C}-\mathrm{H} \mathrm{sp}$; 1633, $59 \mathrm{~cm}^{-1}$ and $1544,88 \mathrm{~cm}^{-1}$ were aromatic bonds of $\mathrm{C}=\mathrm{C}$ and $\mathrm{C}=\mathrm{N}$. The results of characterization using SEM showed that the powder had different diameter as 58, 8 $\mu \mathrm{m} ; 68,3 \mu \mathrm{m}$; and $68,8 \mu \mathrm{m}$ which showed irregularity (amorphous piece).
\end{abstract}

Keywords: Squid ink powder (Loligo sp.), chafastness, Grey Scale, Staining Scale, FT-IR, SEM

\section{Abstrak}

Penelitian ini bertujuan untuk menguji sifat karakter dan karakteristik bubuk tinta cumi. Uji ketahanan luntur menggunakan metode Grey Scale dan Staining Scale, sedangkan uji karakteristik tinta cumi-cumi menggunakan metode FT-IR dan SEM. Hasil yang diperoleh menunjukkan pada saat kain katun dicelupkan ke dalam $250 \mathrm{~mL}$ tinta cumi-cumi selama 1 jam menghasilkan warna hitam namun mudah luntur sehingga warna yang dihasilkan perlu dipertahankan menggunakan fiksator yaitu kapur tohor dan tawas. Variasi konsentrasi fiksator yang digunakan yaitu: 20,50 , dan $100 \mathrm{~g} / \mathrm{mL}$. Hasil yang diperoleh menunjukkan bahwa fiksator kapur tohor menghasilkan warna cokelat, sedangkan fiksator tawas menghasilkan warna hitam pekat. Hasil uji menggunakan Grey Scale dan Staining Scale menunjukkan perlakuan terbaik pada konsentrasi fiksator $100 \mathrm{~g} / \mathrm{mL}$. Selain itu hasil karakterisasi tinta cumi-cumi menggunakan FT-IR menunjukkan adanya serapan pada peak $3236,33 \mathrm{~cm}^{-1}$ merupakan gugus $-\mathrm{OH}$ dan gugus -NH (tumpang tindih); $2964,39 \mathrm{~cm}^{-1}$ dan $2927,74 \mathrm{~cm}^{-1}$ merupakan gugus $\mathrm{C}-\mathrm{H}$ $\mathrm{sp}^{2} ; 1633,59 \mathrm{~cm}^{-1}$ dan $1544,88 \mathrm{~cm}^{-1}$ merupakan ikatan cincin aromatik dari $\mathrm{C}=\mathrm{C}$ dan $\mathrm{C}=\mathrm{N}$. Hasil karakterisasi menggunakan SEM menunjukkan diameter serbuk bervariasi yaitu berukuran $58,8 \mu \mathrm{m} ; 68,3 \mu \mathrm{m}$; dan $68,8 \mu \mathrm{m}$ yang tidak teratur (serpihan amorf).

Kata Kunci: Serbuk tinta cumi-cumi, ketahanan luntur, Grey Scale, Staining Scale, FT-IR, SEM 


\section{Pendahuluan}

Kekayaan laut di Indonesia melimpah untuk dimanfaatkan bagi kepentingan ekonomi dan sosial masyarakat. Sumber daya hayati laut yang ada di perairan Indonesia berupa ikan pelagis besar, ikan pelagis kecil, karang, udang, lobster, dan cumi-cumi. Cumi-cumi merupakan salah satu jenis dari kelas Cephalopoda, yaitu salah satu kelompok binatang lunak yang tidak bertulang belakang. Produksi cumi-cumi di Indonesia dari tahun ke tahun selalu mengalami peningkatan yang sangat singnifikan. Pada tahun 2010 produksi cumi-cumi mencapai 34.925.401 $\mathrm{kg}$ dan pada tahun 2012 terjadi peningkatan yakni sebanyak 58.145.503 kg. Diperkirakan produksi cumi-cumi di Indonesia mencapai 28,25 ribu ton per tahun. Cumi-cumi memiliki suatu kantung tinta yang berfungsi sebagai pertahanan yang akan berkontraksi dan mengeluarkan cairan berwarna hitam di sekitar tubuhnya ketika diserang predator. Tinta cumicumi bersifat alkaloid, sehingga tidak disukai oleh predator, terutama ikan. Alkaloid merupakan kelompok terbesar dari metabolit sekunder yang beratom nitrogen dan bersifat basa. Beberapa alkaloid dterindikasi memiliki manfaat dalam bidang pengobatan. Cairan tinta cumi-cumi umumnya mengandung pigmen melanin yang secara alami terdapat dalam bentuk melanoprotein dengan kandungan melanin $90 \%$, protein $5,8 \%$ dan karbohidrat 0,8\% (Agusandi, dkk., 2013).

Selama ini masih banyak masyarakat yang menganggap tinta cumi-cumi tidak bermanfaat dan hanya sebagai limbah sehingga saat mengolah cumi-cumi membuang tulang rawan dan tinta dari cumi-cumi tersebut. Tulang rawan cumi-cumi dapat dimanfaatkan sebagai bahan dasar pembuatan kitosan (Agusnar, 2007). Sedangkan, tinta cumi-cumi memiliki banyak manfaat dan khasiat. Di Jepang tinta cumi-cumi dipakai sebagai bahan peningkat cita rasa, juga memiliki khasiat untuk kesehatan. Selain itu, menurut Amiruddin (2013), tinta cumi-cumi juga banyak mengandung vitamin A dan dapat mengaktifkan sel darah putih untuk memerangi tumor. Terdapat juga penelitian terdahulu (Ningsih dan Hastuti, 2012) yang meneliti karakteristik senyawa zat warna hitam dari ekstrak teh hitam dan tinta cumi-cumi sebagai bahan pembuatan sel surya organik dengan menggunakan metode spektrofotometer UVVIS, hasilnya menunjukan kisaran daerah serapan panjang gelombang ekstrak teh hitam yaitu 232-240 nm dan ekstrak tinta cumi-cumi 203-207 nm yang mengindikasikan adanya transisi elektron pada tingkatan orbital tertentu.

Pemanfaatan limbah tinta cumi-cumi belum banyak, tetapi di Nusa Tenggara Timur khususnya di Kabupaten Alor, limbah tinta cumi-cumi sudah dimanfaatkan sebagai bahan tambahan dalam proses diversifikasi produk. Salah satu produk yang telah dilakukan diversifikasi adalah kain tenun ikat. Tenunan ini merupakan salah satu bentuk industri rumah tangga yang dikenal secara turun-temurun dalam masyarakat. Untuk memperindah kain tenun ikat diperlukan pewarna yang akan memberikan corak dan motif dari kain yang dihasilkan. Penggunaan pewarna alami memiliki banyak kelemahan, namun banyak keraguan bila terus menggunakan pewarna sintetis karena limbah pewarna sintetis memiliki dampak negatif pada lingkungan hidup. Salah satu pewarna sintetis Malachite green yang digunakan untuk proses pencelupan. Pewarna ini termasuk senyawa organik yang mempunyai gugus amino, imino, dan juga dikombinasikan dengan asam seperti $\mathrm{HCl}$. Di lingkungan, kadar pewarna sintetis yang diperbolehkan di perairan adalah 0,01 ppm. Pewarna sintetis ini mempunyai kemiripan senyawa organik dengan limbah tinta cumi-cumi yang digunakan untuk masyarakat Alor, NTT dalam memanfaatkan tinta sebagai pewarna alami (Sukmawati dan Utami, 2014).

Untuk mempertahankan tinta cumi-cumi yang digunakan sebagai bahan pewarna kain tenun ikat dilakukan dengan penambahan fiksator. Jenis fiksator yang sering digunakan adalah $\mathrm{K}_{2} \mathrm{SO}_{4} \cdot \mathrm{Al}_{2}\left(\mathrm{SO}_{4}\right)_{3}$ (tawas), $\mathrm{Ca}(\mathrm{OH})_{2}$ (kapur tohor), dan $\mathrm{FeSO}_{4}$ (tunjung). Fiksasi merupakan proses untuk memperkuat warna agar tidak mudah luntur. Dengan demikian, tujuan penggunaan fiksator adalah untuk menetralkan dan membangkitkan zat pewarna yang telah masuk ke dalam serat tekstil (Kartikasari dan Susiati, 2016). Jenis fiksator yang digunakan ternyata dapat memberikan respon yang tidak sama dalam mengikat warna sehingga berpengaruh terhadap kecerahan dan arah warna (Pujilestari, 2017). 
Zat pewarna tinta cumi-cumi dalam bentuk cair sifatnya mudah mengalami perubahan organoleptik yakni terjadi aroma yang menyengat yang mengindikasikan tinta cumicumi reaktif dengan keadan suhu kamar, sehingga sulit untuk disimpan dalam jangka waktu yang lama. Oleh karena itu, untuk mengatasi hal tersebut maka perlu dilakukan pengeringan untuk mendapatkan butiran serbuk pewarna yang efektif dan dapat disimpan lebih lama tetapi tetap memiliki kemampuan sebagai pewarna alami untuk kain tenun ikat. Pemanfaatan lainnya juga perlu dilakukan karena sifat dari serbuk tinta cumi-cumi yang tidak mudah larut didalam air. Dengan demikian sebelum dimanfaatkan perlu dilakukan karakterisasi menggunakan metode SEM dan FT-IR. Pengujian karakterisasi menggunakan metode SEM bertujuan untuk mengamati struktur maupun bentuk permukaan partikel sedangkan metode FT-IR bertujuan untuk mengetahui gugus-gugus fungsi yang terdapat dalam serbuk tinta cumi-cumi. Dengan demikian sangat penting untuk melakukan penelitian tentang uji ketahanan luntur dan karakterisasi serbuk tinta cumi-cumi (Loligo sp.) sebagai dasar pewarna hitam untuk kain tenun ikat asal Nusa Tenggara Timur.

\section{Metode Penelitian}

\section{Alat dan Bahan}

Tinta cumi-cumi (Loligo sp.) dari pasar tradisional kelurahan Oesapa, Kota Kupang; kain katun; benang tenun berwarna putih; kapur tohor $\left(\mathrm{Ca}(\mathrm{OH})_{2}\right)$; tawas $\left(\mathrm{Al}_{2}\left(\mathrm{SO}_{4}\right)_{2} \mathrm{H}_{2} \mathrm{O}\right)$; etil asetat p.a; pelet $\mathrm{KBr}$; oven; centrifuge; Scanning Electron Microscope (SEM); FT-IR; beberapa peralatan gelas yang sudah disterilkan; dan air destilasi.

\section{Prosedur Uji Ketahanan Luntur dari Tinta Cumi-cumi (Loligo sp.)}

Kantung tinta cumi-cumi diambil kemudian dibersihkan dengan air sampai bersih. Setelah itu, tinta cumi-cumi dikeluarkan dari kantungnya ke dalam wadah yang sudah disiapkan. Perlakuan lainnya dilakukan terhadap kain katun untuk proses mordating dengan cara sebanyak $2 \mathrm{~L}$ air dipanaskan lalu ditambahkan $100 \mathrm{~g} / \mathrm{L}$ tawas hingga mencapai suhu $\pm 35^{\circ} \mathrm{C}-$ $45^{\circ}$ C. Selanjutnya kain katun direndam selama 1 jam ke dalam campuran sambil diaduk. Kemudian api dimatikan dan kain direndam selama 1 malam. Tahap terakhir adalah kain diangkat dan dibilas dengan air panas dan air dingin secara bergantian kemudian dikeringkan.

Kain yang sudah dikeringkan kemudian dicelupkan ke dalam larutan tinta cumi-cumi yang telah disiapkan sebanyak $300 \mathrm{~mL}$ selama 1 jam. Selainnya kain difiksasi dengan cara di rendam ke dalam $50 \mathrm{~g} / \mathrm{L}$ tawas; $100 \mathrm{~g} / \mathrm{L}$ tawas; $50 \mathrm{~g} / \mathrm{L}$ kapur tohor; dan $100 \mathrm{~g} / \mathrm{L}$ kapur tohor masing-masing selama 1 jam. Kemudian kain diangkat, dikeringkan. Kemudian, dilakukan pengujian ketahanan luntur warna terhadap kain katun yang telah dihasilkan dengan pencucian dan penodaan warna menggunakan metode Grey scale dan Staining Scale (dibandingkan dengan skala pada Photoshop). Prosedur uji ketahanan luntur juga dilakukan pada pembuatan benang tenun ikat asal NTT.

\section{Prosedur Pembuatan Serbuk Tinta Cumi- cumi (Loligo sp.)}

Sebanyak $120 \mathrm{~mL}$ tinta cumi-cumi (Loligo sp.) disentrifugasi pada kecepatan 2000 rpm selama 5-10 menit. Ekstrak kental yang diperoleh dikeringkan didalam oven hingga berbentuk butiran serbuk warna hitam pada suhu $60{ }^{\circ} \mathrm{C}$. Setelah itu dilakukan prosedur seperti pada tahapan uji ketahanan luntur dari serbuk tinta cumi-cumi dengan cara terlebih dahulu serbuk diencerkan menggunakan larutan etil asetat (diujikan hanya pada benang tenun ikat).

\section{Karakterisasi Serbuk Tinta Cumi-cumi (Loligo sp.)}

Proses karakterisasi serbuk tinta cumicumi menggunakan metode FT-IR dan SEM. Metode FT-IR untuk mengetahui gugus fungsi penting yang ada pada serbuk sedangkan SEM digunakan untuk mengetahui bentuk dan ukuran pori dari serbuk yang dihasilkan.

\section{Hasil dan Pembahasan}

\section{Uji Ketahanan Luntur dari Tinta Cumi-cumi (Loligo sp.)}

Tinta cumi-cumi (Loligo sp.) mengandung zat warna hitam yang merupakan senyawa 
melanin. Zat melanin dapat digunakan sebagai pewarna alami maupun pewarna tekstil. Khususnya di NTT (pulau Alor) digunakan sebagai pewarna kain tenun ikat yang dapat memberikan warna hitam. Tinta cumi-cumi yang digunakan tidak diubah dalam bentuk lainnya. Tinta yang diambil langsung diaplikasikan pada benang yang digunakan dalam proses pembentukan kain tenun ikat. Proses modifikasi tinta ke bentuk serbuk bertujuan untuk penyimpanan tinta sebagai pewarna kain tenun dalam jangka waktu yang lama.

Pada proses pembuatan serbuk tinta cumicumi menggunakan jenis Loligo sp. terlihat pada Gambar 1.a. Bagian tinta yang diambil (Gambar 1.b) kemudian dimanfaatkan untuk pewarnaan kain 'tenun ikat'. Sebelum direndam dalam tinta cumi-cumi kain terlebih dulu dicelupkan ke dalam campuran tawas agar warna hitam yang dihasilkan nantinya tidak mudah luntur. Pada Gambar 1.c terlihat bahwa kain katun berwarna hitam menunjukkan kain katun mampu menyerap zat warna dari tinta cumi-cumi. Hal yang sama juga dibuktikan pada Gambar 1.f terlihat bahwa benang kain tenun yang dicelupkan kedalam larutan serbuk tinta cumicumi berwarna hitam. Hal ini membuktikan bahwa serbuk tinta cumi-cumi bisa digunakan pada proses pembuatan kain tenun berwarna dasar hitam. Untuk kegunaan dalam waktu yang lama, tinta cumi-cumi diubah menjadi serbuk tinta (Gambar 1.d). Serbuk yang dihasilkan tidak mudah larut di dalam air tetapi larut dalam etil asetat (Gambar 1.e) karena sifat melanoprotein yang semipolar dan juga bersifat sebagai antioksidan yang baik. Dengan demikian, untuk memudahkan dalam pelarutan serbuk maka digunakan etil asetat untuk melarutkan terlebih dahulu kemudian ditambahkan air untuk memudahkan proses pencelupan.

Hasil uji ketahanan luntur tinta cumi-cumi dan serbuknya diperlihatkan dalam Tabel 1 . Untuk mempertahankan warna kain hasil pencelupan digunakan tawas dan kapur tohor sebagai fiksator. Tujuan penggunaan fiksator yaitu dapat mengikat perwarna pada tinta cumicumi. Kedua jenis fiksator ini mudah larut di dalam air sehingga aplikasinya menjadi lebih mudah. Penggunaan fiksator memengaruhi tingkat ketahanan luntur pada pencelupan benang kain tenun maupun kain katun. Pengaruh penggunaan fiksator yang berbeda dapat memberikan warna yang berbeda (Gambar 2). Pada Gambar 2 terlihat bahwa penggunaan jenis fiksator kapur tohor menghasilkan perubahan warna hitam (b) ke warna kecoklatan (d), sedangkan fiksator tawas menghasilkan warna hitam (Gambar 2 c dan e) pada konsentrasi yang berbeda. Tingkat ketahanan luntur dan perubahan warna dibuktikan dengan membandingkan warna yang terbentuk pada saat pencelupan dengan standar grey scale dan Staining scale. Tabel 1 (a) dan (b) menunjukkan perbedaan antara proses pencelupan serbuk tinta cumi-cumi menggunakan jenis kain yang berbeda. Tabel 1 (b) menunjukkan pencelupan kain katun pada $100 \mathrm{~g} / \mathrm{mL}$ fiksator memberikan hasil warna hitam yang terbaik (tingkat kelunturan 4, kategori baik), sedangkan pada Tabel 1 (a) benang kain tenun dicelup pada 20 $\mathrm{g} / \mathrm{mL}$ fiksator (tingkat kelunturan 4, kategori baik). Hal ini membuktikan bahwa jenis bahan tenun yang digunakan juga mempengaruhi tingkat warna yang dihasilkan. Dengan demikian, tinta cumi-cumi dapat dimanfaatkan sebagai pewarna alami baik digunaka tintanya secara langsung maupun diubah menjadi serbuk. 


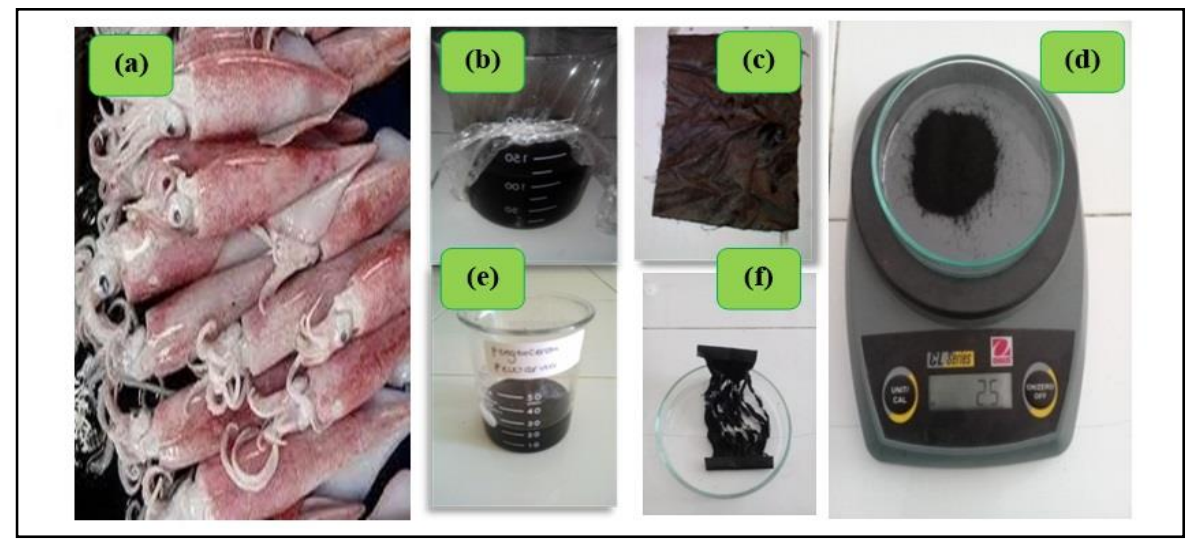

Gambar 1. (a). Cumi-cumi (Loligo sp.); (b). Tinta cumi-cumi; (c). Hasil pencelupan kain katun dalam tinta cumi-cumi; (d). Serbuk tinta cumi-cumi yang di timbang; (e). Hasil pengenceran serbuk tinta cumi-cumi menggunakan etil asetat; (f). Hasil pencelupan benang kain tenun ikat ke dalam serbuk tinta cumi-cumi yang sudah diencerkan dengan etil asetat.

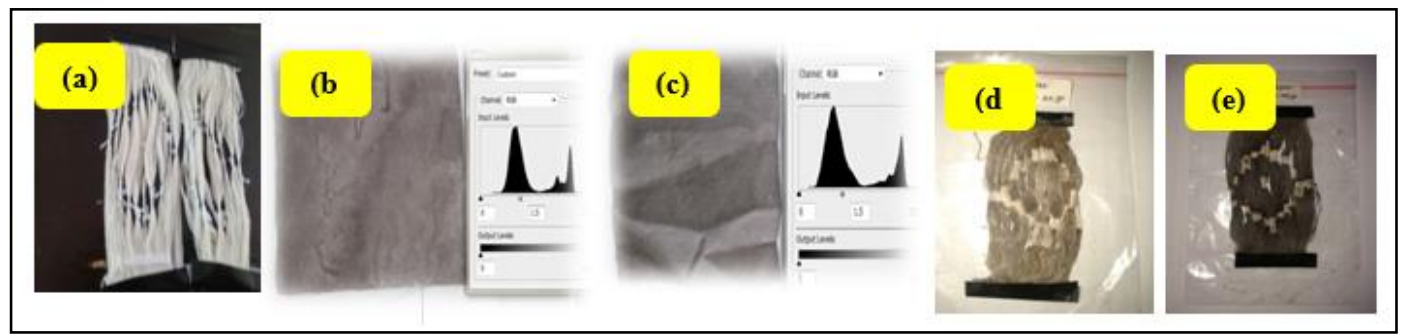

Gambar 2. Hasil Pencelupan Kain Katun dan Benang Kain Tenun: (a) Benang kain tenun yang dibuat pola/model motif tenun; (b). Hasil pencelupan kain katun dalam $100 \mathrm{~g} / \mathrm{mL}$ kapur tohor; (c). Hasil pencelupan kain katun dalam $100 \mathrm{~g} / \mathrm{mL}$ tawas; (d). Hasil pencelupan benang kain tenun dalam $20 \mathrm{~g} / \mathrm{mL}$ kapur tohor; dan (e). Hasil pencelupan benang kain tenun dalam $20 \mathrm{~g} / \mathrm{mL}$ tawas

Tabel 1. Hasil Uji Ketahanan Luntur

\begin{tabular}{|c|c|c|}
\hline \multicolumn{3}{|c|}{$\begin{array}{l}\text { a) Hasil uji pada benang kain tenun ikat yang } \\
\text { dicelupkan ke dalam larutan serbuk tinta cumi- } \\
\text { cumi (dalam etil asetat) }\end{array}$} \\
\hline Percobaan $(\mathrm{g} / \mathrm{mL})$ & $\begin{array}{l}\text { Nilai Color } \\
\text { defference }\end{array}$ & Keterangan \\
\hline \multicolumn{3}{|c|}{ Tawas } \\
\hline 20 & 1,5 & 4 (Baik) \\
\hline \multicolumn{3}{|c|}{ Kapur tohor } \\
\hline 20 & 1,5 & 4 (Baik) \\
\hline
\end{tabular}

b) Hasil uji pada kain katun yang dicelupkan ke dalam larutan tinta cumi-cumi (Loligo sp.)

\section{Karakterisasi serbuk tinta cumi-cumi}

Serbuk tinta cumi-cumi dianalisis menggunakan FT-IR dan SEM. Hasil analisis spektroskopi FT-IR dari serbuk tinta cumi-cumi jenis Loligo sp. dengan serbuk jenis Sepia

\begin{tabular}{ccc}
\hline \hline Percobaan $(\mathbf{g} / \mathbf{m L})$ & $\begin{array}{c}\text { Nilai Color } \\
\text { defference }\end{array}$ & Keterangan \\
\hline \hline \multicolumn{3}{c}{ Tawas } \\
\hline \hline 0 & 6,0 & 2 (Kurang) \\
50 & 2,1 & $3-4$ (cukup baik \\
100 & 1,5 & 4 (baik) \\
\hline \hline \multicolumn{3}{c}{ Kapur tohor } \\
\hline 0 & 6,0 & 2 (kurang) \\
100 & 2,1 & 3-4 (cukup baik \\
1,5 & (baik) \\
\hline \hline
\end{tabular}

officinalis (Mbonyiryipuze dkk., 2015). Hasilnya menunjukkan beberapa puncak serapan yang merupakan gugus fungsi untuk menyatakan adanya zat warna melanin. Puncak vibrasi melebar diperlihatkan di daerah $3236,33 \mathrm{~cm}^{-1}$ 
yang menunjukan bahwa pada daerah ini terdapat gugus $\mathrm{O}-\mathrm{H}$ dan $\mathrm{N}-\mathrm{H}$, serapan pada bilangan gelombang $2964,39 \mathrm{~cm}^{-1}$ dan 2927,74 $\mathrm{cm}^{-1}$ menunjukan adanya ikatan $\mathrm{C}-\mathrm{H} \mathrm{sp}{ }^{2}$, serapan pada bilangan gelombang $1633,59 \mathrm{~cm}^{-1}$ dan $1544,88 \mathrm{~cm}^{-1}$ menunjukan adanya ikatan cincin aromatik dari $\mathrm{C}=\mathrm{C}$ dan $\mathrm{C}=\mathrm{N}$, serapan yang muncul pada bilangan gelombang $1400,22 \mathrm{~cm}^{-1}$ dan $1340,43 \mathrm{~cm}^{-1}$ menunjukkan adanya vibrasi pada O-H fenolik dan kelompok karboksil, serapan yang muncul pada bilangan gelombang $1045,35 \mathrm{~cm}^{-1}$ menunjukan bahwa dapat membantu memperkuat vibrasi $\mathrm{C}-\mathrm{H}$ secara inplane maupun $\mathrm{C}-\mathrm{H}$ out-of plane dan serapan yang muncul pada bilangan gelombang 790,76 $\mathrm{cm}^{-1}$ membantu memperkuat ikatan $\mathrm{C}-\mathrm{H}$ pada cincin aromatik secara out of plane. Perkiraan puncak vibrasi yang menunjukkan adanya zat warna melanin diperlihatkan pada Gambar 3 (a) dan (b), serta Tabel 2.
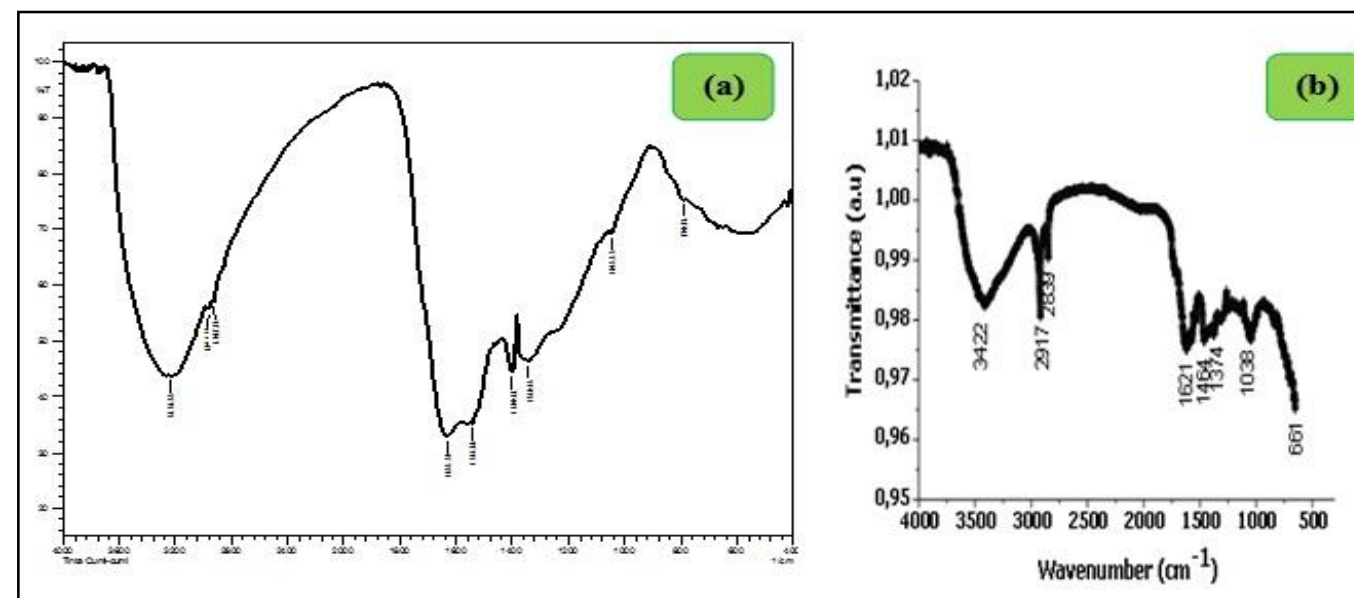

Gambar 3. Hasil analisis menggunakan Spektroskopi FT-IR: (a). Serbuk Loligo sp.; (b). serbuk Sepia officinalis (Mbonyiryipuze, dkk., 2015)

Tabel 2. Bilangan gelombang dan gugus fungsi serbuk tinta cumi-cumi ; (a) Loligo sp.; (b) Sepia officinalis

\begin{tabular}{|c|c|c|c|c|}
\hline \multirow[t]{2}{*}{ 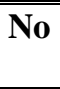 } & \multicolumn{2}{|c|}{ Bilangan Gelombang $\left(\mathrm{cm}^{-1}\right)$} & \multicolumn{2}{|c|}{ Gugus Fungsi } \\
\hline & $\mathbf{A}$ & B & $\overline{\mathbf{A}}$ & B \\
\hline 1 & 3236,33 & 3422 & $\mathrm{O}-\mathrm{H}$ dan N-H & Puncak vibrasi O-H atau N-H \\
\hline 2 & $\begin{array}{l}2964,39 \text { dan } \\
2927,74\end{array}$ & 2917 dan 2839 & Tumpang tindih antara $\mathrm{C}-\mathrm{H} \mathrm{sp}^{2}$ & $\begin{array}{l}\text { Puncak vibrasidari kelompok C-H } \\
\text { Alifatik }\end{array}$ \\
\hline 3 & $\begin{array}{l}1633,59 \text { dan } \\
1544,88\end{array}$ & 1621 & $\begin{array}{l}\text { Model vibrasi ikatan cincin } \\
\text { aromatik dari } C=C \text { dan } C=N \text { untuk } \\
\text { memperkuat vibrasi utama }\end{array}$ & $\begin{array}{l}\text { Model vibrasi ikatan cincin aromatik } \\
\text { dari } \mathrm{C}=\mathrm{C} \text { dan } \mathrm{C}=\mathrm{N} \text { untuk } \\
\text { memperkuat vibrasi utama }\end{array}$ \\
\hline 4 & $\begin{array}{l}1400,22 \text { dan } \\
1340,43\end{array}$ & 1464,1374 & $\begin{array}{l}\text { Memperkuat vibrasi C-H sp }{ }^{2} \text { dan } \\
\text { menunjukkan adanya vibrasi pada } \\
\text { O-H Fenolik dan kelompok } \\
\text { karboksil }\end{array}$ & $\begin{array}{l}\text { Memperkuat vibrasi } \mathrm{C}-\mathrm{H} \text { alifatik dan } \\
\text { menunjukkan adanya vibrasi pada O- } \\
\text { H Fenolik dan kelompok karboksil }\end{array}$ \\
\hline 5 & 1045,35 & 1038 & $\begin{array}{l}\text { Memperkuat vibrasi } \mathrm{C}-\mathrm{H} \text { secara } \\
\text { in-plane maupun } \mathrm{C}-\mathrm{H} \text { out-of plane }\end{array}$ & $\begin{array}{l}\text { Memperkuat vibarasi } \mathrm{C}-\mathrm{H} \text { secara in- } \\
\text { plane maupun } \mathrm{C}-\mathrm{H} \text { out-of plane }\end{array}$ \\
\hline 6 & 790,76 & 666 & $\begin{array}{l}\text { Memperkuat ikatan } \mathrm{C}-\mathrm{H} \text { pada } \\
\text { cincin aromatik secara out of } \\
\text { plane }\end{array}$ & $\begin{array}{l}\text { Memperkuat ikatan } \mathrm{C}-\mathrm{H} \text { pada cincin } \\
\text { aromatik secara out of plane }\end{array}$ \\
\hline
\end{tabular}

Untuk mengetahui bentuk, morfologi, dan porositas dari serbuk tinta cumi-cumi (Loligo sp.) maka dilakukan pengujian menggunakan Scanning Electron Microscope (SEM). Hasil analisis serbuk tinta cumi-cumi menggunakan SEM dapat dilihat pada Gambar 4.

Hasil SEM pada perbesaran 100× (Gambar 4.a) dan 300× (Gambar 4.b) terlihat bahwa serbuk tinta cumi-cumi yang diperoleh 
berbentuk serpihan-serpihan amorf (bentuk tidak beraturan). Partikel serbuk yang dihasilkan memiliki ukuran diameter yang beragam yaitu sebesar 58,8 $\mu \mathrm{m}, 68,3 \mu \mathrm{m}$, dan $68,8 \mu \mathrm{m}$. Hal ini terjadi karena saat proses penghancuran tidak merata, sehingga distribusi ukuran partikel tinta cumi-cumi menjadi tidak beraturan. Selanjutnya hasil analisis menggunakan perbesaran 500x (Gambar 4.c), 1000× (Gambar 4.d), dan 1200x (Gambar 4.e) diketahui bahwa banyak butiranbutiran serbuk tinta cumi-cumi yang menempel antara partikel yang satu dan lainnya. Hasil analisis juga tidak menunjukkan pori dari serbuk yang dihasilkan.



Gambar 4. Hasil analisis SEM serbuk tinta cumi-cumi (Loligo $s p$.) pada perbesaran: (a). 100x; (b). 300x; (c). 500x; (d). 1000x; dan (e). $1200 \times$.

\section{Simpulan}

Tinta cumi-cumi (Loligo sp.) digunakan sebagai pewarna alami untuk kain tenun ikat asal Provinsi Nusa Tenggara Timur. Uji daya tahan luntur untuk warna hitam yang dihasilkan dibutuhkan fiksator jenis tawas dan kapur tohor. Selain dimanfaatkan sebagai pewarna kain tenun ikat, tinta cumi-cumi juga diubah menjadi bentuk serbuk dan dikarakterisasi berdasarkan gugus fungsi dan bentuk partikel. Hasil ini dapat dipergunakan untuk keperluan lain karena bentuk partikel dari serbuk yang dihasilkan adalah serpihan amorf. Dibutuhkan aktivasi untuk meningkatkan kemampuan dari serbuk yang dihasilkan agar penggunaannya menjadi lebih luas.

\section{Daftar Pustaka}

Agusandi, Supriadi, A. dan Lestari, S. D. 2013. Pengaruh Penambahan Tinta Cumi-cum (Loligo sp.) Terhadap Kualitas Nutrisi Dan Penerimaan Sensoris Mie Basah. Universitas Sriwijaya Indralaya Ogan Ilir 2 (01): 22-37.

Amiruddin. 2013. Membangun Sumber Daya Kelautan Indonesia. IPB Press.

Kartikasari, E. dan Susiati, Y.T. 2016. Pengaruh Fiksator pada Ekstrak Daun Mangga dalam Pewarnaan Tekstil Batik Ditinjau dari Ketahanan Luntur Warna Terhadap Keringat. Jurnal Sciencetech, 2 (1): 136-143.

Ningsih, R. dan Hastuti, E. 2012. Karakterisasi Ekstrak Teh Hitam dan Tinta Cumi-cumi sebagai Fotosensitiser pada Sel Surya berbasis Pewarna Tersensitisasi. Sainstis UIN Maliki Malang 1 (2): 47-55. 


\section{Merpiseldin Nitsae dkk.}

Pujilestari, T. 2017. Optimasi Pencelupan Kain Batik Katun dengan Pewarna Alam Tinggi (Ceriops tagal) dan Indigofera $\mathrm{Sp}$. Dinamika Kerajinan dan Batik, 34 (1): 53-62.
Sukmawati, P. dan Utami, B. 2014. Adsorpsi Zat Pewarna

Tekstil Malachite green Menggunakan Adsorben Kulit Buah Kakao (Theobroma cacao) Teraktivasi $\mathrm{HNO}_{3}$. Prosiding: Seminar Nasional Fisika dan Pendidikan Fisika (SNFPF) ke-5, 5 (1): 19-25. 